\title{
ANALISIS VEGETASI PADA KAWASAN TAMAN NASIONAL GUNUNG MERAPI
}

\author{
Arifah Nuha Imtiyaz ${ }^{*}$, Dhiya Khairunnisa Islami Hana², Dyah Ayu Sekarini ${ }^{3}$, Haris \\ Ristomo $^{4}$, Putri Anjani Nawang Bulan ${ }^{5}$, Sidiq Fajri' ${ }^{6}$, Thengku Indriyenni Maretha ${ }^{7}$ \\ 1, 2, 3, 4, 5, 6, 7 Jurusan Pendidikan Biologi, Fakultas MIPA, Universitas Negeri Yogyakarta, Indonesia \\ Email: arifahnuha.2018@student.uny.ac.id
}

Received: Oktober $3^{\text {th }}, 2019$. Accepted: November $2^{\text {nd }}, 2019$. Published: December $29^{\text {th }}, 2019$

\begin{abstract}
This study aims to analyze the vegetation in the area of Mount Merapi National Park (TNGM) by observing the importance value index and the shannon index obtained. Quadrant sampling method is used for vegetation analysis. The results show that from all stations analyzed, despite a long succession process and many significant changes, the stability of diversity in the TNGM region is still low.
\end{abstract}

Keywords: Quadrant Sampling; Succession; Important Value Index; Shannon Index; Merapi.

\begin{abstract}
Abstrak
Penelitian ini bertujuan untuk menganalisis vegetasi di kawasan Taman Nasional Gunung Merapi (TNGM) dengan memperhatikan indeks nilai penting dan indeks shannon yang didapat. Metode Quadrant sampling digunakan untuk analisis vegetasi. Didapatkan hasil bahwa dari semua stasiun yang dianalisis, walaupun sudah berjalan proses suksesi sejak lama dan sudah banyak perubahan yang signifikan, kestabilan dari keanekaragaman di wilayah TNGM masih rendah.
\end{abstract}

Kata Kunci: Quadrant Sampling; Suksesi; Indeks Nilai Penting; Indeks Shannon; Merapi.

\section{PENDAHULUAN}

Erupsi gunung Merapi berdampak terhadap ekosistem dan vegetasi di sekitarnya (Gunawan dkk. 2015). Bebrapa aktivitas vulkanik yang dapat berdampak terhadap vegetasi diantaranya lahar dan gas piroklastik, gas panas (awan panas) yang dapat mencapai suhu $700^{\circ} \mathrm{C}$ (Nurhadi, Ashari, dan Suparmini 2017). Peristiwa Erupsi Merapi saat itu menjadi penyebab terjadinya suksesi baik primer maupun sekunder di wilayah yang sekarang dijadikan sebagai Taman Nasional Gunung Merapi (Herawati 2012). Perwakilan daerah yang menjadi tempat terjadinya suksesi primer, dimana akibat dari erupsi tersebut terjadi kerusakan hebat hingga tidak tersisa vegetasi setelah erupsi (Sari 2017).

Kerusakan lahan akibat erupsi diantaranya berupa hilangnya beberapa atau banyak plasma nutfah dan berubahnya biodiversitas tumbuhan, hilangnya daerah tangkapan air, 
rusaknya hutan, tertutupnya sumber air, serta hilangnya saluran saluran air (Rahayu dkk. 2014). Terkuburnya tanah dan terhambatnya pembentukan tanah akibat erupsi yang berulang-ulang pada gunung Merapi, hilangnya jalan-jalan akses ke lahan pertanian dan hilangnya batas -batas kepemilihan lahan oleh erupsi dan lahar dingin (Rahayu dkk. 2014). Merapi sudah tidak pernah terlihat adanya aktivitas erupsi yang berarti hingga saat ini. Hal ini mengundang perhatian peneliti untuk mengetahui bagaimana struktur vegetasi yang ada pada kawasan TNGM tersebut pada masa sekarang dengan melakukan analisis vegetasi di lingkungan tersebut.

Analisis vegetasi mempelajari susunan komposisi spesies dan bentuk struktur vegetasi atau masyarakat tetumbuhan. Analisis Vegetasi yang dilakukan di Gunung Merapi melibatkan strata vegetasi tumbuhan yang dibagi menjadi beberapa kelompok habitus, yaitu lumut, herba, semak, dantegakan. Lumut menjadi tumbuhan tingkat rendah yang hidup di lingkungan lembab. Dikarenakan Habitat lumut secara umum terdapat pada batang pohon, kayu lapuk, batuan dan tanah. Tumbuhan lumut penting sebagai perintis di tanah - tanah yang gundul, seperti lumut hati yang pada umumnya memainkan peranan kecil sebagai pengisi vegetasi yang tinggi. Lumut hati sebagai pembantu dalam mengikat dan memantapkan permukaantanah yang mengalami erosi (Fitantri 2017).

Herba tumbuhan yang tingginya sampai dua meter, Herba juga memiliki daya saing yang kuat dan adaptasi yang tinggi terhadap tumbuhan disekitarnya (seperti semak, perdu, bahkan pohon) sehingga mampu tumbuh di tempat yang kosong (Laratu, Pitopang, dan Suleman 2014). Semak tumbuhan berkayu yang tingginya lebih dari satu meter, tetapi lebih rendah daripada perdu dan hanya dahan-dahan utamanya saja yang berkayu (Arisandy dan Triyanti 2018). Diantaranya Pohon yang mempunyai batang pokok tunggal yang menunjang tajuk berdaun dari cabang-cabang di atas tanah. Pohon tersusun oleh banyak bagian. Penelitian ini bertujuan untuk menganalisis vegetasi di Kecamatan Cangkringan, Kabupaten Sleman, Daerah Istimewa Yogyakarta (Kawasan Taman Nasional Gunung Merapi).

\section{METODE}

Penelitian dilakukan pada hari Jum'at, 11 Oktober 2019 di kawasan Taman Nasional Gunung Merapi, Sleman, Yogyakarta. Pengambilan data dilakukan di Bendung Kali Gendol, Bunker Kaliadem, Watu Gajah, sekitar Pendopo Mbah Maridjan, Jalur 
Pendakian Merapi, dan arah Hulu Kali Kuning menggunakan metode Quadrant Sampling.

Alat dan bahan yang digunakan pada penelitian kali ini berupa tali rafia, patok, meteran, alat tulis, lembar kerja, milimeter block, alat dokumentasi, dan alat-alat klimatik edafik berupa higrometer, soil tester, termometer udara, dan lux meter. Teknik yang digunakan pada penelitian kali ini berupa teknik quadrant sampling.

Teknik ini dilakukan dengan mencari luas minimal plot dan jumlah minimal plot. Diawali dengan membuat daerah sampling berbentuk segiempat menggunakan patok dan tali rafia dengan luas awal 2x2 $\mathrm{m}$ lalu mendata ada berapa jumlah spesies yang ditemukan. Selanjutnya membuat daerah sampling lebih luas yakni dengan menambahkan luas daerah sampling menjadi $2 \times 4 \mathrm{~m}$, lalu dilakukan pendataan kembali ada berapa spesies baru yang dapat ditemui pada luas daerah yang baru tersebut. Selanjutnya membuat daerah sampling kembali menjadi lebih luas dengan menjadikan luas daerah sebesar $4 \times 4 \mathrm{~m}$, lalu $4 \mathrm{x} 8 \mathrm{~m}$, dan seterusnya, sambil diambil data sampai tidak ditemukan penambahan spesies baru. Prinsipnya jika tidak ditemukan spesies baru, maka pengambilan data juga selesai dan dilanjutkan dengan pengolahan data dengan membuat grafik pada milimeter block.

Dilakukan dengan cara yang sama seperti mencari luas plot minimal, namun menggunakan luas minimal plot yang sudah didapat, dan tempat sampling bebas asal tetap berada pada lingkungan tersebut, dengan mengutamakan daerah yang dianggap paling representatif. Dilakukan dengan membuat daerah sampling pada tempat yang dianggap paling representatif dengan ketentuan jumlah minimal plot dan luas minimal plot yang sduah didapatkan sebelumnya, lalu melakukan pengambilan data di plot-plot tersebut dengan mendata spesies apa saja yang ditemukan, jumlah individu perspesies, bagaimana habitus yang ditemukan, serta data klimatik edafik.

\section{HASIL DAN PEMBAHASAN}

Berdasarkan hasil analisis vegetasi pada Kawasan Taman Nasional Gunung Merapi, diketahui bahwa berikut ini. 
Tabel 1. Analisis Vegetasi Klimatik Edafik

\begin{tabular}{lcc}
\hline \multicolumn{1}{c}{ Keterangan } & Plot $\mathbf{1}$ & Plot 2 \\
\hline Suhu udara & $38,6 \mathrm{C}$ & $38,6 \mathrm{C}$ \\
Kelembaban udara & $21 \%$ & $21 \%$ \\
Intensitas cahaya & $1275 \mathrm{~cd}$ & $1278 \mathrm{~cd}$ \\
Kecepatan angin & Max: $6,1 \mathrm{~m} / \mathrm{s} \mathrm{Min:} 2,1 \mathrm{~m} / \mathrm{s}$ & Max: $6,1 \mathrm{~m} / \mathrm{s} \mathrm{Min:} 2,1 \mathrm{~m} / \mathrm{s}$ \\
Arah angin & Selatan & Selatan \\
pH tanah & $\mathbf{7}$ & $\mathbf{7}$ \\
Kelembaban tanah & $35,2 \%$ & $35,2 \%$ \\
tekstur tanah & Berpasir & Berpasir \\
\hline
\end{tabular}

Semakin besar nilai INP suatu spesies semakin besar tingkat penguasaan terhadap komunitas dan sebaliknya (Soegianto, 1994 dalam (Budiwan, Fahrizal, dan Prayogo 2018). Penguasaan spesies tertentu dalam suatu komunitas dapat dilihat apabila spesies yang bersangkutan berhasil menempatkan sebagian besar sumberdaya yang ada dibandingkan dengan spesies yang lainnya (Saharjo dan Cornelio, 2011 dalam (Budiwan, Fahrizal, dan Prayogo 2018). Pada kegiatan, Lumut yang ditemukan berupa Hypnum cupressiforme. Memiliki indeks nilai penting tertinggi yakni 300\%, menandakan dominansi yang cukup kuat dalam komunitasnya (Frahm 2009).

Dengan persamaan yang telah disebutkan, didapatkan indeks nilai shannon dari masing - masing stasiun tiap habitusnya yakni sebagai berikut:

Tabel 2. Indeks Nilai Shannon Dari Masing - Masing Stasiun Tiap Habitus

\begin{tabular}{lcccccc}
\hline \multicolumn{1}{c}{ Habitus } & St1 & St2 & St3 & St4 & St5 & St6 \\
\hline Lumut /Lichenes & 0 & 0 & 0 & 0,450488 & 0,523458 & 0,128492316 \\
Herba & 0,464738 & 0,870975 & 0,734014 & 0,683294 & 0 & 0,402609229 \\
Semak & 0,50889 & 0,154544 & 0,426673 & 1,090747 & 0,822474 & 0,231993036 \\
Tegakan & 0 & 0 & 0 & 0,276822 & 0,94175 & 0,304967242 \\
\hline
\end{tabular}

Berdasarkan Tabel 2 hasil perhitungan tersebut di dapat bahwa semua habitus baik pada stasiun 1, 2, 3, 4, 5, maupun stasiun 6 nilai indeks shannon nya bernilai dibawah 1 , menandakan bahwa walaupun suksesi pada kawasan Taman Nasional Gunung Merapi telah berjalan cukup lama dengan perubahan yang signifikan, kestabilan dari biodiversitasnya masih rendah atau dikatakan masih kurang stabil. 
Brachypodium retusum terdapat kelembaban menjadi salah satu faktor pembatas untuk pertumbuhan dan reproduksi tanaman yang mengarah pada adaptasi kekeringan (Vidaller 2018; Shah dan Paulsen 2003; Suriyagoda dkk. 2010). Namun, peningkatan kelembaban tanah sering mengakibatkan persaingan yang lebih tinggi untuk sumber daya lain yang mewakili kekuatan selektif penangkal (Vidaller 2018). Selain itu, paku sayur (pakis) juga dapat tumbuh di daerah rindang, lembab, hutan dan rawarawa (Mcglone, Wilmshurst, dan Leach 2005). Semak yang ditemukan berupa Panicum maximum, Cymbopogon citratus, Anaphalis javanica, dan Amarantus tuberculatus, termasuk tanaman berumur panjang (tahunan) yang dapat tumbuh tegak, kuat, batang seperti padi dengan tinggi 2-2,5 m (Suswati 2012) Tumbuh sangat baik di daerah teduh di bawah pohon dan semak. Heliophyte (tumbuh subur di bawah intensitas cahaya tinggi) dan nitrofil (tumbuh subur di tanah yang kaya nitrogen) (Robinson 2017) Amaranthus tuberculatus tumbuh baik di tanah yang subur, kaya nutrisi. Kisaran toleransi $\mathrm{pH}$ antara 4,5 dan 8,0, sementara spesies memiliki sedikit toleransi tanah salin tinggi tetapi memiliki beberapa toleransi $\mathrm{CaCO} 3$. Amaranthus tuberculatus telah ditemukan berhasil tumbuh pada suhu siang / malam yang berkisar di antaranya 25/20 dan 35/30 C (Schryver 2017).

Kepunahan edelweiss di daerah pegunungan memicu terjadinya erosi dan tanah longsor, serta kondisi tanah di daerah pegunungan yang minim edelweiss akan mempengaruhi perkembangan pada tumbuhan lain, karena keberadaan bunga edelweiss dengan aroma semerbak mengundang banyak jenis serangga untuk menikmati madunya, serangga yang mati di sekitar edelweiss menjadi pupuk organik yang ikut menyuburkan tanah (Gemasih dkk 2017). Erupsi menyebabkan keadaan tanah menjadi berpasir serta berbatu, ditambah kelembaban tanah yang jadi berkurang.

Pertumbuhan Bryoflora epifit akan dipengaruhi oleh kelembaban tempat tersebut dan intensitas cahaya yang cukup. Selain itu, suhu pada lokasi kegiatan juga memungkinkan untuk Bryoflora bertahan hidup karena Bryoflora pada kawasan tropis dapat hidup pada suhu diatas 25C. Leucobryum glaucum dapat ditemukan pada ketinggian sekitar 980 mdpl pada koordinat 07o 09'659'LS-110o 20'014'BT dengan kelembaban $60 \%$, suhu 26,5oC, dan intensitas cahaya 3.900 cd (Mulyani, Perwati, dan Murningsih 2014) kondisi klimatik edafik pada stasiun ini dianggap masih cukup untuk spesies ini tumbuh dengan baik sehingga cukup mendominasi dan mengakibatkan tingginya indeks nilai penting. 
Terminalia cattapa punya indeks nilai penting yang turut menempati posisi tertinggi. Tumbuh baik di tanah berpasir yang kering, (Thomson dan Evans 2006) hal ini sesuai dengan karakteristik lingkungan di stasiun 2 yang kering dan berpasir sehingga indeks nilai pentingnya tinggi walaupun seharusnya ia cenderung ditemukan di pantai dan pinggir sungai, karena sesuai dengan lingkungannya sehingga cukup menguasai sumber daya disana.

Tingkat penyebaran bambu baik secara alami maupun disengaja ditanam yang dapat ditemui di daerah datar, lembah, perbukitan dan dataran tinggi kecuali daerah gurun dan rawa, dan umumnnya menyukai tempat-tempat yang subur, terbuka, dan kelerengan datar hingga berbukit (Sofiah 2013). Tanaman semak berumpun banyak tumbuh liar di lereng gunung, tanggul, lapangan rumput, dan sisi jalan di daerah berhawa sejuk (Indriyanti dkk. 2015). Spesies ini termasuk kedalam spesies tumbuhan pionir dalam suatu proses suksesi.

Beberapa rumput tidak mampu hidup di bawahnya lereng gunung. Kejadian ini kemungkinan disebabkan karena kompetisi kebutuhan cahaya atau adanya factor alelopati (Djufri 2013) dan kemungkinan inilah yang memungkinkan indeks nilai penting dari Acacia tinggi. Diketahui Ageratina dapat tersebar dengan mudah oleh air dan angin sehingga dapat menyebar dengan cepat kedaerah yang lebih luas (Hidayat 2012) sedangkan diketahui stasiun 3 butuh air dan angin yang cukup untuk menyebarkan spesies ini. Tamarindus indica memiliki akar yang bertipe akar tunjang yang kuat membuat pohon kokoh dan tidak mudah rebah. Kanopi pohon asam bagus untuk tujuan penahan angin karena tidak mudah patah jika terkena angin (Setiawan 2018)

Pohon asam berumur tahunan, dikategorikan tumbuhan dikotil dengan ciri-ciri mempunyai daun lebat kecil berumpun, potensi berbatang besar, batang tanaman keras, buah polong bergerombol, warna buah kecoklatan (Setiawan 2018). Ditemukan juga Agrimonia yang menyukai cahaya matahari dan tumbuh pada suhu sedang yang lembab dan kering tanah. (Ivanova dkk. 2011). Batang kayu yang sudah lapuk merupakan media atau tempat yang baik bagi pertumbuhan lumut karena kayu yang sudah lapuk banyak menyerap atau menyimpan air di antara sel-sel kayunya sehingga memiliki kelembaban yang tinggi dan zat-zat yang diperlukan oleh tumbuhan lumut untuk menunjang pertumbuhannya.

Tumbuhan lumut yang tumbuh di lantai hutan dapat menahan erosi, mengurangi bahaya banjir dan mampu menyerap air sehingga dapat menyediakan air pada musim 
kemarau (Liana 2018) hal ini cukup menjadi penyebab mengapa indeks nilai penting dari tumbuhan ini menjadi yang tertinggi di stasiun ini. Kondisi pun cukup panas walau rimbun, menyebabkan kedelai kurang cocok untuk hidup di lingkungan tersebut sehingga dominansinya sangatlah kecil dan indeks nilai pentingnya juga menjadi kecil (Taufiq 2012).

Melastoma malabatrichum dikenal sebagai akumulator $\mathrm{Al}$ mucilage akar berperan dalam peningkatan akumulasi Al. mucilage berfungsi untuk meningkatkan serapan $\mathrm{Al}$ (Sopandie 2013). Pertumbuhan lumut karena kayu yang sudah lapuk banyak menyerap atau menyimpan air di antara sel-sel kayunya sehingga memiliki kelembaban yang tinggi dan zat-zat yang diperlukan oleh tumbuhan lumut untuk menunjang pertumbuhannya (Putri 2019). Tumbuhan lumut yang tumbuh di lantai hutan dapat menahan erosi, mengurangi bahaya banjir dan mampu menyerap air sehingga dapat menyediakan air pada musim kemarau (Liana 2018).

\section{SIMPULAN DAN SARAN}

Beradasarkan hasil peneltian maka dapat disimpulkan bahwa Indeks nilai penting tertinggi dari setiap stasiun cenderung dimiliki oleh kelompok habitus lumut dan lichenes. Hal ini disebabkan karena kelompok tersebut merupakan kelompok tumbuhan yang seirng menjadi tumbuhan pionir dalam suatu proses suksesi. Dilihat dari indeks shannon, semua stasiun baik dengan habitus lumut dan lichenes, herba, semak dan tegakan walaupun proses suksesi sudah berlangsung seak lama dan perubahan yang terlihat sudah banyak peningkatan secara signifikan namun setelah dianalisis ternyata masih kurang stabil, menandakan bahwa ekosistem di kawasan TNGM masih belum seimbang baik dengan faktor mekanisme penyimpanan bahan/materi, pelepasan unsur hara, pertumbuhan populasi, produksi, dan penguraian/dekomposisi.

Hal ini dapat dilihat dari bagaimana persebaraan dan pemerataan spesies dari tiap stasiun. Adapun saran untuk penelitian selanjutnya supaya dapat diadikan rujukan dan dapat dikembangkan lagi untuk vegetasi lainnya.

\section{DAFTAR PUSTAKA}

Arisandy, Destien Atmi, dan Merti Triyanti. 2018. "Keanekaragaman Jenis Vegetasi Strata Semak di Hutan Perlindungan Kawasan Bukit Cogong." BIOEDUSAINS: Jurnal Pendidikan Biologi dan Sains 1 (2): 95-105. https://doi.org/10.31539/bioedusains.v1i2.362. 
Budiwan, Arie, Fahrizal, dan Hari Prayogo. 2018. "Analisa Vegetasi Pada Pengelolaan Hutan Tradisional Masyarakat Suku Dayak Tamambaloh Dan Iban Di Wilayah Redd+ Kphp Model Kapuas Hulu (Vegetation” 6: 246-53.

Djufri. 2013. "pengaruh tegakan akasia (acacia nilotica) (1.) Willd. Ex. Del. Terhadap komposisi dan keanekaragaman tumbuhan bawah di savana balanan taman nasional baluran jawa timur." Jurnal Biologi Edukasi 3 (2): 38-50.

Fitantri, Ratih. 2017. "Inventarisasi Dan Keanekaragaman Tumbuhan Lumut (Bryophyta) Di Kawasan Giribangun Wetankali Girilayu Matesih Karanganyar Jawa Tengah Disusun.”

Frahm, JP. 2009. "A preliminary study of the infraspecific taxa of Hypnum cupressiforme in Europe." Arch Bryol 40 (2009): 1-10.

Gemasih dkk, 2017. 2017. "Jurnal Ilmiah Mahasiswa Fakultas Keguruan dan Ilmu Pendidikan Unsyiah Vol 2, No 1 (2017); Pebruari 2017” 2 (1): 8-14.

Gunawan, HENDRA, N. M. Heriyanto, E. Subiandono, A. F. Mas'ud, dan H. Krisnawati. 2015. "Invasi jenis eksotis pada areal terdegradasi pasca erupsi di Taman Nasional Gunung Merapi." Dalam Prosiding Seminar Nasional Masyarakat Biodiversiti Indonesia, 1:1027-33.

Herawati, Nenden Ineu. 2012. "Pendidikan Inklusif." EDUHUMANIORA: Jurnal Pendidikan Dasar 2 (1).

Hidayat, Angga Zaelani. 2012. "Keanekaragaman Dan Pola Penyebaran Spasial Spesies Tumbuhan Asing Invasif Di Cagar Alam Kamojang." Экономика Региона, nо. August: 32.

Indriyanti, Wiwiek, Rizki Desvianto, Ida Musfiroh, Fakultas Farmasi, Universitas Padjadjaran, dan Jawa Barat. 2015. "Inulin dari Akar Jombang ( Taraxacum officinale Webb .) sebagai Prebiotik dalam Yoghurt Sinbiotik Inulin from Jombang Root ( Taraxacum officinale Webb .) as Prebiotic in Synbiotic Yoghurt” 2.

Ivanova, Diana G, Oskan Tasinov, Deyana Vankova, dan Yoana Kiselova-kaneva. 2011. "Antioxidative potential of Agrimonia eupatoria L," no. May 2014.

Laratu, Mohammad Iqbal N, Ramadhanil Pitopang, dan Samsurizal M Suleman. 2014. "Hutan Di Desa Bobo Kawasan Taman Nasional Lore Lindu" 8 (2): 13-25.

Liana, Alin. 2018. "Identifikasi Tumbuhan Lumut di Kawasan Wisata Taman Nasional Bantimurung," 147-51.

Mcglone, Matt S, Janet M Wilmshurst, dan Helen M Leach. 2005. "An ecological and historical review of bracken ( Pteridium esculentum ) in New Zealand, and its cultural significance" 29: 165-84. 
Mulyani, Eka, Lilih Khotim Perwati, dan Murningsih Murningsih. 2014. "Lumut Daun Epifit Di Zona Tropik Kawasan Gunung Ungaran, Jawa Tengah.” Bioma : Berkala Ilmiah Biologi 16 (2): 76. https://doi.org/10.14710/bioma.16.2.76-82.

Nurhadi, Nurhadi, Arif Ashari, dan Suparmini Suparmini. 2017. "Karakteristik Lingkungan Dan Infrastruktur Kaitannya Dengan Tingkat Kesiapsiagaan Di Kawasan Rawan Bencana Erupsi Merapi." Geomedia: Majalah Ilmiah dan Informasi Kegeografian $15(2)$.

Putri, shela erika. 2019. "Fakultas Kehutanan Universitas Tanjungpura Pontianak. Jl. Daya Nasional Pontianak 78124" 7: 1036-47.

Rahayu, Rahayu, Dwi Priyo Ariyanto, Komariah Komariah, Sri Hartati, Jauhari Syamsiyah, dan Widyatmani Sih Dewi. 2014a. "Dampak Erupsi Gunung Merapi terhadap Lahan dan Upaya-Upaya Pemulihannya." Caraka Tani: Journal of Sustainable Agriculture 29 (1): 61-72.

. 2014b. "Dampak Erupsi Gunung Merapi Terhadap Lahan Dan Upaya-Upaya Pemulihannya." Caraka Tani: Journal of Sustainable Agriculture 29 (1): 61. https://doi.org/10.20961/carakatani.v29i1.13320.

Robinson, D. 2017. "The distribution and control of glyphosate-resistant waterhemp ( Amaranthus tuberculatus var . rudis ) in soybean ( Glycine max ) in Ontario By Mike G . Schryver University of Guelph , 2017 Advisors :"

Sari, Desi Edian. 2017. "Pendampingan masyarakat Desa Tasikmadu dalam upaya pengurangan risiko bencana hidrometeorologi melalui pemetaan partisipatif tata ruang desa dengan SIG (Sistem Informasi Geografis) dan SID (Sistem Informasi Desa) sebagai media penyadaran masyarakat.” UIN Sunan Ampel Surabaya.

Schryver, Mike G. 2017. "The distribution and control of glyphosate-resistant waterhemp ( Amaranthus tuberculatus var . rudis ) in soybean (Glycine max ) in Ontario By Mike G . Schryver University of Guelph , 2017 Advisors :"

Setiawan, Eko. 2018. "Keragaman Populasi Pohon Asam (Tamarindus indica L.) di Jalan Raya Socah-Arosbaya, Kabupaten Bangkalan dan Strategi Konservasi." Rekayasa 11 (2): 95. https://doi.org/10.21107/rekayasa.v11i2.4446.

Shah, N. H., dan G. M. Paulsen. 2003. "Interaction of drought and high temperature on photosynthesis and grain-filling of wheat." Plant and Soil 257 (1): 219-226.

Sofiah, Siti. 2013. "Ekologi dan bioprospeksi bambu di kawasan taman wisata alam gunung baung pasuruan jawa timur siti sofiah."

Sopandie, Didy. 2013. Fisiologi Adaptasi Tanaman terhadap Cekaman Abiotik pada Ekosistem Tropika. 
Suriyagoda, Lalith DB, Megan H. Ryan, Michael Renton, dan Hans Lambers. 2010. "Multiple adaptive responses of Australian native perennial legumes with pasture potential to grow in phosphorus-and moisture-limited environments." Annals of botany 105 (5): 755-67.

Suswati. 2012. "Pertumbuhan Dan Produksi Rumput Benggala (Panicum maximum) Pada Berbagai Upaya Perbaikan Tanah Salin” 1 (1): 55-68.

Taufiq, Abdullah. 2012. “Lingkungan Tumbuh” 26 (23): 13-26.

Thomson, L A J, dan B Evans. 2006. "Species Profiles for Pacific Island Agroforestry Terminalia catappa (tropical almond)." Species proPles for Pacipc Island Agroforestry, no. January 2006.

Vidaller, Christel. 2018. "Adaptive differentiation among populations of the Mediterranean dry grassland species Brachypodium retusum: The role of soil conditions, grazing, and humidity" 105 (6): 1-10. https://doi.org/10.1002/ajb2.1116. 